\title{
Práticas laboratoriais e a história na cena: tecnologia e iluminação na cena épica de Piscator $^{1}$
}

\section{Laboratory practices and the history in the scene: technology and lighting in the Piscator epic scene}




\section{Resumo}

O presente artigo apresenta algumas reflexões e resultados a partir da prática integrada de pesquisa desenvolvida no âmbito do Grupo de Pesquisa em História, Política e Cena - GPHPC/UFSJ, em suas dimensões de investigação, formação e difusão. Para tal, apresentamos as bases teóricas de pesquisa - a partir da noção de cena dialética e sua relação entre a cena e a história no trabalho do diretor Erwin Piscator (1893-1966) - e as práticas laboratoriais que resultaram no experimento cênico Confere. Nesse conjunto, destacam-se os procedimentos desenvolvidos no GPHPC/UFSJ quanto à prática cênica e no Núcleo de Estudos de Técnicas e Ofícios da Cena - Netoc quanto ao desenvolvimento da iluminação cênica para esse espetáculo e seus aspectos históricos e épicos, pensados concomitantemente ao momento do desenvolvimento tecnológico da iluminação elétrica e seus impactos na cena.

Palavras-chaves: História da iluminação cênica; direção teatral; teatro épico; Erwin Piscator; laboratórios teatrais

\section{Abstract}

This article presents some reflections and results from the integrated research practice developed within the Grupo de Pesquisa em História, Política e Cena - GPHPC/UFSJ (Research Group in History, Politics and Scene), in its dimensions of research, training and dissemination. To this end, we will present the theoretical bases of research - from the notion of dialectical scene and the relationship between scene and history, in the work of director Erwin Piscator (1893-1966) - and the laboratory practices that resulted in the scenic experiment Confere (Confers). In this set, we highlight the procedures developed in GPHPC/UFSJ regarding the scenic practice and in the Núcleo de Estudos de Técnicas e Ofícios da Cena - Netoc (Center for Studies of Techniques and Crafts of Cena) regarding the development of scenic lighting for this show and its historical and epic aspects thought concomitantly at the time of technological development of electric lighting and its impacts on the scene.

Keywords: History of scenic lighting; theatrical direction; epic theatre; Erwin Piscator; theatrical laboratories 
.... lugar do intelectual na luta de classes só pode ser definido - ou melhor, escolhido - por sua posição no processo produtivo.

...para o autor como produtor, o progresso técnico é a base de seu progresso político.

Seu trabalho não envolverá apenas os produtos, mas sempre, simultaneamente, os meios de produção. Em outras palavras, ao lado do caráter de obra, seus produtos devem ter uma função organizadora.

Um autor que não ensina nada aos que escrevem não ensina nada a ninguém.

(Benjamin, 2017, p. 85-99)

A prática laboratorial tem sido eixo e essência a marcar o fazer artístico teatral de forma particular desde as últimas décadas do século XIX (Schino, 2012, p. VII-XI). E caracteriza um direcionamento dos objetivos do fazer artístico para outros campos que não apenas o produto como resultado do trabalho, mas o próprio trabalho em seus aspectos de formação e de desenvolvimento de conhecimento e reflexão sobre o teatro. Seguindo tais traços, a prática laboratorial também tem sido considerada componente fundamental, portanto, para as atividades que possuem como fim primeiro a formação e o desenvolvimento de conhecimentos, como é o caso da universidade.

Paradoxalmente, o termo laboratório teatral veio a ser empregado como o oposto de performance. Em todo caso, ele indica todos aqueles teatros nos quais a preparação de apresentações não é a única atividade. Mas criar um espetáculo pode também ser uma tarefa intrincada, orgânica e labiríntica, usualmente o oposto de um processo linear. Portanto, o termo laboratório teatral é às vezes utilizado como um símbolo que representa a existência de um caminho criativo complexo ou, de algum modo, diferente. (Schino, 2012, p. VIII).

O Grupo de Pesquisa em História, Política e Cena da Universidade Federal de São João del-Rei - GPHPC/UFSJ (<www.dgp.cnpq.br/dgp/espelhogrupo/5893650868206891>) tem seguido o princípio da prática laboratorial em suas atividades cotidianas, visando desenvolver projetos e ações que integrem pesquisa (desenvolvimento de conhecimentos e reflexões), ensino (formação) e extensão (difusão e troca de práticas e conhecimentos) no campo teatral. Estruturado atualmente em dois núcleos de trabalho, que direcionam as ações para dois campos de intenso diálogo - Núcleo de Estudos de Teatro Político: Encenação e Núcleo de Estudos de Técnicas e Ofícios da Cena: Iluminação Cênica, Netep e Netoc, respectivamente - , 0 GPHPC hoje se organiza em torno de pesquisas individuais, vinculadas a um desses núcleos, profundamente interligadas, com forte caráter laboratorial e investigativo, e que se encontram de forma contundente na prática cênica do Coletivo Fuzuê ${ }^{4}$. 0

\footnotetext{
4 O Coletivo Fuzuê, à época do desenvolvimento do experimento cênico aqui focalizado era composto por: Ana Paula Milagres Tostes (voluntária), Bárbara Fátima dos Santos Lara (bolsista de iniciação científica/UFSJ), Beatriz Valquíria Ribeiro (bolsista de Iniciação Artística/Proex/UFSJ), Carlos Henrique Aurélio dos
} 
presente artigo terá como base de análise o processo de trabalho desenvolvido pelos dois Núcleos do GPHPC e seu resultado, o experimento cênico Confere ${ }^{5}$, desenvolvido pelo Coletivo Fuzuê.

O Coletivo Fuzuê, desdobramento do Netep - inicialmente um núcleo de estudo de práticas de direção e encenação teatral -, se caracteriza como um grupo de teatro universitário de pesquisa, ensino e extensão formado por alunos dos cursos de licenciatura e bacharelado em teatro e do mestrado em artes cênicas da UFSJ, sob coordenação da professora doutora Carina Maria Guimarães Moreira. O Netoc ${ }^{6}, \mathrm{co}^{-}$ ordenado pelo professor doutor Berilo Luigi Deiró Nosella, dedica-se a atividades de ensino, pesquisa e extensão em iluminação cênica e também é formado por alunos desses três segmentos da UFSJ. O Netoc vem desenvolvendo um modo de trabalho em que os projetos de criação de luz (que constituem uma das ações continuadas do Núcleo) são realizados pelo coordenador tendo um/uma aluno/aluna responsável por ele, embora o processo e os resultados sejam acompanhados e debatidos por todo o grupo 7 . No caso do experimento Confere, o desenho de luz foi desenvolvido dessa forma, sob supervisão geral do coordenador do Netoc, sendo debatido por todos e na responsabilidade da aluna Beatriz Freitas Nitoli Leme, tendo-se optado por constar na ficha técnica o seguinte crédito: "Iluminação - Netoc-GPHPC/UFSJ; coordenação Berilo L. D. Nosella; responsável Beatriz Nitoli".

O presente artigo é, portanto, resultado parcial das pesquisas "Cena dialética: práxis e história", coordenada pela professora Carina M. G. Moreira, e "Iluminação cênica e metateatro: o fazer e o pensamento da iluminação entre o real e o ficcional", coordenada pelo professor Berilo L. D. Nosella (com financiamento de CNPq e Fapemig), e apresenta parte das reflexões conjuntas, no campo da encenação e da iluminação cênica, sobre o trabalho e a teoria do encenador alemão Erwin Piscator (1893-1966), e da prática laboratorial de encenação, realizada a partir dessas reflexões, junto ao Coletivo Fuzuê, na elaboração do Confere - experimento cênico desenvolvido ao longo de 2018, tendo estreado em 23 de novembro daquele ano, no evento II Seminário em História, Política e Cena, organizado pelo GPHPC em São João del-Rei ${ }^{8}$, e que tem desde então viajado a diversos lugares e instituições, tanto

\footnotetext{
Santos (mestrado), Héricles Gomes de Araújo (bolsista de iniciação científica/UFSJ) e Jhonata Francisco Castorino (bolsista de iniciação científica/UFSJ).

5 Confere é um experimento cênico que aborda questões referentes aos dilemas democráticos no Brasil. Suas cenas intercalam presente e passado, narrando de forma intricada histórias sobre o início de nossa república, da ditadura militar decretada em 1964 e acontecimentos atuais, evidenciando a violência com as comunidades periféricas e os consequentes problemas de desigualdades sociais, que são encontrados até hoje no país. 0 experimento foi desenvolvido no âmbito do Grupo de Pesquisa em História, Política e Cena da Universidade Federal de São João del-Rei com alunos do curso de graduação em teatro e pós-graduação em artes cênicas, sob direção e coordenação da professora Carina Maria Guimarães Moreira (texto da sinopse presente no material de divulgação do trabalho).

6 Desde a época do desenvolvimento do Confere o Netoc é composto por: Beatriz Freitas Nitoli Leme (bolsista de Iniciação Artística/Proex/UFSJ), Fernanda Fontes (bolsista de Iniciação Artística/Proex/UFSJ), Isabela Francisconi (bolsista de Iniciação Científica/CNPq/UFSJ), Laura Resende (bolsista de Iniciação científica/CNPq), Bruna Guimarães (bolsista de Iniciação Científica/UFSJ), Hadrien Nogueira (monitor do laboratório de iluminação - Sala Preta/Deace/UFSJ), Fernanda Junqueira (estagiária do Laboratório de lluminação - Sala Preta/Deace/UFSJ).
}

7 Até 2019 (um ano após o desenvolvimento do experimento Confere e ano de redação do presente artigo), o Netoc centrava suas atividades de estudos no campo da iluminação cênica. A partir deste ano, seguindo a vocação já presente no momento de escolha de seu nome (Estudos de Técnicas e Ofícios), o Netoc iniciou a ampliação de suas atividades para o campo da cenotécnica e cenografia, e ainda abriga o desejo de ampliar para o audiovisual, sonoridade, indumentária, etc., pensando sempre a questão das técnicas e a noção de ofícios na cena.

8 Disponível em <https://www.even3.com.br/iishpc ufsj_2018/?fbclid=lwAR0EVow-ZvxJxF2XBnDM5ApYBXPtpnXYuuYO7XeWHJ7EiopVS344KoQ2wrk> e <https://ufsj.edu.br/gphpc/>. 
apresentando o experimento ${ }^{9}$ quanto realizando seminários teórico-práticos sobre os métodos de trabalho dos núcleos em seus respectivos campos de atuação ${ }^{10}$.

\section{Piscator e o teatro político}

Teatro político, livro escrito por Erwin Piscator em 1929, teve sua primeira e única edição no Brasil em 1968, pela Civilização Brasileira. Na obra, Piscator traz algumas formulações teóricas sobre seu teatro, nomeado teatro político, bem como apresenta quadro social em narrativa pessoal que vai ao encontro dos acontecimentos históricos de sua época. Esse quadro é a base que lhe permite realizar uma formulação cênica que, como veremos adiante, propõe a elevação das cenas particulares ao histórico (Piscator, 1968, p. 157).

Essa proposição do encenador parte de sua convicção e seu empenho em prol da transformação social, e, dessa forma, traz o entendimento do fazer teatral como uma ação para revolução, abrindo caminho, por meio da obra de arte, para assuntos de cunho político e social, opondo-se à subjetividade por excelência, própria dos ambientes privados do drama burguês. Neste artigo, trazemos para reflexão alguns elementos estruturantes desse teatro e que norteiam nosso atual laboratório cênico.

\section{O teatro de Piscator: a montagem cinematográfica e a cena simultânea}

Para compreender o contexto das produções de Piscator a partir dos anos 1920, no período da República de Weimar (1918-1933), realizadas em sua maioria no Teatro Volksbüne, de Berlim, incluímos a seguir um breve esboço histórico, ajudados por Anatol Rosenfeld (1993) em seu livro História da literatura e do teatro alemães. Na passagem do século XIX para o XX surgem na Alemanha duas associações teatrais a Freie Bühne (Cena Livre) e a Freie Volksbüne (Cena Popular Livre). A primeira foi criada em 1889 nos moldes do Théâtre-Libre (1887) (Teatro Livre) de André Antoine (1858-1943), uma associação teatral que encenava peças modernas (naturalistas) para seus membros e, assim, conseguia driblar os mecanismos de censura da época. A Freie Volksbüne, de 1890, seguiu os moldes de associação da Freie Bühne, porém, seu objetivo era "oferecer ao povo mais modesto arte de alta categoria. 'A arte deve pertencer ao povo e não deve ser privilégio [...] de apenas uma classe social', declarou na ocasião Bruno Wille, um dos fundadores" (Rosenfeld, 1993, p. 314). Em 1914, a Freie Volksbüne constrói sua sede própria, o Teatro Volksbüne, de Berlim, no qual, em 1924, Piscator realiza uma primeira experiência, com o espetáculo Bandeiras, e cuja

\footnotetext{
9 Itinerário do Confere: 23/11/2018, estreia no II Seminário do GPHPC/CTAN/UFSJ (São João del-Rei/MG); 26/11/2018, Escola Estadual Professor lago Pimentel (São João del-Rei/MG); 08/12/2018, Quilombo da Pontinha (Paraopebas/MG); 18/02/2019, UnB Campus Darcy Ribeiro (Brasília/DF); 20/02/2019, Centro Educacional São Francisco (São Sebastião/DF); 21/02/2019, Praça Diogo Teles (Cavalcante/GO); 25/02/2019, Centro Educacional Taquara (Planaltina/DF); 10/05/2019, Escuela de Teatro Politico de Buenos Aires (Argentina); 04/07/2019, Escola Estadual Conego Osvaldo Lustosa (São João del-Rei/MG); 07/07/2019, Festival de Inverno de Ouro Preto e Mariana (Ouro Preto/MG); 31/08/2019, I Feira de Arte Política na ocupação urbana Marielle Franco (Florianópolis/SC); 01/09/2019, ocupação urbana Nova Esperança (Palhoça/SC); 04/09/2019, Teatro da União Beneficente Recreativa Operária - Teatro UBRO (Florianópolis/SC); 05/09/2019, Teatro da UFSC (Florianópolis/SC); 06/09/2019, comunidade do Rio Vermelho (Florianópolis/SC); 15/10/2019, Escola de Artes do MST Sudeste João das Neves (Belo Horizonte/MG).

10 Os seminários de iluminação foram realizados nas seguintes instituições: Unesp, UnB, Universidad Nacional de las Artes - UNA (Buenos Aires), Unespar, Udesc e UFU.
} 
direção assume até 1927, quando, devido a questões políticas e ideológicas, dele se desvincula e parte para o projeto de um teatro próprio.

Sua entrada no Volksbüne permite a Piscator ter em mãos os aparatos cênicos e técnicos mais completos e modernos de sua época, viabilizando suas experimentações cênicas, principalmente com a projeção de imagens e filmes em cena, que são referência até os dias de hoje.

Em Apesar de tudo! (1925), Piscator utiliza o filme como elemento cênico pela primeira vez e afirma que "Todo o espetáculo foi uma única montagem de autêntico discurso, redação, recortes de jornal, conclamações, folhetos, fotografias e filmes da guerra e da revolução, de personagens e cenas históricas" (Piscator, 1968, p. 82). Esse exemplo nos possibilita vislumbrar como, desde o princípio, a utilização de aparatos técnicos tinha como objetivo incorporar à cena fragmentos documentais da realidade para a criação de um ambiente histórico.

Piscator destaca o fato de que o uso do filme nesse trabalho foi muito valorizado, tanto pela crítica mais entusiasmada com seu trabalho quanto por aquela que o depreciava. Chama atenção o emprego de duas linguagens na época consideradas rivais. Especulava-se ainda a possibilidade de influência dos russos, e, quanto a isso, Piscator (1968, p. 81) afirma não ter tido contato com essa produção, embora acredite que seus trabalhos poderiam ter fatores em comum, pois tanto seu teatro quanto o russo constituíam "uma forma de teatro apreendida ao nascer e baseada na filosofia histórico-marxista". Interessava-lhe não apenas a propagação dessa filosofia, mas a demonstração de sua validade e de sua importância para a época. Piscator explica que para isso procurou trabalhar um nexo entre os elementos cênicos particulares e individuais dos personagens com os grandes fatores sociais e históricos, e o filme, nesse caso, entrara exatamente como esse meio para a criação do nexo entre o particular e o histórico, criando camadas de leitura.

Tais camadas de leitura eram formadas por algo que poderíamos chamar de "camadas de cena", diversas linguagens, tanto visuais quanto sonoras, referentes à cena e fornecidas pelo filme e por projeções. É o que será legado aos séculos XIX e XX, como a ideia de cenas simultâneas, que se relacionam à ideia de multiplicidades de vozes (coralidade) e discursos. Dessa experiência em 1925 com as projeções, Piscator irá, com o passar dos anos, empreender outros experimentos com a ideia de cenas simultâneas utilizando tecnologias que se faziam disponíveis. Já em 1927, em Oba! Estamos vivendo, ele posiciona várias camadas de projeção inseridas na cena. Segundo Cristina Grazioli (2015, p. 180), o efeito de isolar a cena e fragmentá-la, proposto pela forma de iluminar expressionista no início do século XX, é realizado por Piscator nessa encenação, utilizando diversas outras tecnologias, além da luz elétrica. Mais à frente, porém, veremos como já na década de 1950 Piscator (2013) irá radicalizar sua visão sobre os potenciais da luz ao pensar a ideia de um "cenário de luz", no qual toda a lógica narrativa da cena seria modificada pela tecnologia da iluminação elétrica. Todo o seu raciocínio formal e de uso da tecnologia, entretanto, perpassa seu pensamento sobre a presença da história na cena.

No ensaio "A revista política [Piscator]", Peter Szondi (2001) sugere a aproximação da obra de Piscator com as técnicas desenvolvidas pelo cinema da época. Essa aproximação se dá não apenas no campo mais óbvio, da utilização dos filmes 
na encenação, mas das técnicas descobertas no início do século $X X$, que trariam ao cinema o status de linguagem artística, como, por exemplo, a mudança de plano, o close e a montagem de imagens. Ao analisar o trabalho de Piscator, podemos verificar que a linguagem épica dialética se desenvolve na cena pelo emprego da técnica, representada pela utilização de filmes, projeções e iluminação cênica, bem como pela construção cenográfica e contrapontos entre os aparatos técnicos, cênicos e dramatúrgicos. Sobre a questão, Peter Szondi (2001, p. 132) comenta:

\begin{abstract}
Mas a inclusão do filme na encenação direciona o drama político social para o épico, e não apenas por causa da épica imanente ao cinema. A justaposição entre o fato no palco e o fato na tela também tem um efeito epicizante (já que relativisador). A ação cênica deixa de fundamentar a totalidade da obra em sua natureza absoluta. Essa totalidade já não surge mais dialeticamente do fato intersubjetivo, senão que resulta da montagem de cenas dramáticas e relatos cinematográficos, além de coros, projeções de calendário, indicações de diversas ordens, entre outras coisas. A relativização interna e recíproca das partes é enfatizada no plano espacial pelo "palco simultâneo", empregado por Piscator de diversas formas.
\end{abstract}

Szondi nos apresenta aqui a possibilidade de pensar a construção da cena dialética em Piscator a partir da noção de montagem cinematográfica. Tal noção, profundamente explorada pelo cinema de vanguarda da esquerda soviética no início do século $X X$, revela-se um ponto-chave de análise não apenas da cena, mas da composição de um pensamento que se propunha a favor da revolução. Um tipo de arte e pensamento que procurava questionar o status quo, portanto, questionar a própria história. Uma das personalidades que muito contribuíram para a teoria e a prática da montagem foi o diretor Serguei Eisenstein (1898-1948), para quem a montagem não é mera justaposição de imagens visando à criação de um significado, mas antes a ideia de que "O pensamento humano é montagem, e a cultura humana é resultado de um processo de montagem onde o passado não desaparece e sim se reincorpora, reinterpretado, no presente" (Eisenstein, 2017, posição 44). Da mesma forma, Eisenstein afirma que a montagem não é específica da linguagem cinematográfica - embora seja a linguagem cinematográfica responsável por um alto grau de experimentação da montagem -, que sua experiência com montagem se inicia no teatro e que a ideia de montagem já se encontrava na pintura "nas vistas de Toledo feitas por El Greco", nos "princípios básicos do circo e do music-hall" ou na "montagem-cruzada de diálogos em Madame Bovary" (posições 52, 310 e 317).

Assim, quando aliamos as proposições cênicas de Piscator - o uso de aparatos tecnológicos, como projeções, filmes, iluminação; suas proposições espaciais, como palcos construídos com diferentes planos, esteiras rolantes e palcos giratórios; ou mesmo a composição entre esses elementos tecnológicos e espaciais - com a noção de montagem, é possível compreender a estruturação do que chamamos de cena simultânea, na qual, a dialética se apresenta como base. Para compor uma cena efetivamente dialética, Piscator se utiliza dos aparatos cenográficos e tecnológicos, trazendo para o público a possibilidade de fruir uma obra teatral que trabalha os elementos cênicos de forma relativizada - como nos chama atenção Szondi -, abrindo uma seara de experimentações no campo da cena épica. 


\section{A questão da luz na cena de Piscator: outra noção do histórico, para além do contexto}

Se a projeção do filme é fundamental no teatro de Piscator, exatamente porque a incorporação do aparato tecnológico disponível a partir da segunda revolução industrial (1850-1870) em seu teatro é um ato político duplo - na incorporação da tecnologia em si e nas transformações narrativas e de produção que essa incorporação promove em seu teatro -, também o é a iluminação, assim como para todos os encenadores do período ligados ao processo de epicização da cena. Em termos históricos do desenvolvimento da linguagem da cena, o que vemos é a possibilidade de "deslocamento" narrativo do espaço, proporcionado pelos novos meios de controle da iluminação elétrica. Talvez um dos grandes ganhos técnicos/estéticos da iluminação elétrica (não único, mas fundamental) seja a capacidade total de controle, centralizado e a distância, das fontes luminosas, individualmente ou em grandes grupos. O que estamos chamando de "capacidade total de controle" vincula-se à possibilidade, até aquele momento impossível em toda a história da iluminação, de se acender, apagar e novamente acender a fonte luminosa a distância. Esse potencial de controle total e individual das fontes possibilitou acender, com rapidez e sem interferência direta na cena, luzes tanto com características diversas (angulação, cor etc.) quanto em locais diversos da cena. Isso resolvia uma questão central para o teatro épico em oposição às premissas do drama, que era a quebra da unidade de espaço.

Não há dúvida de que a França, nos anos 20, segue os passos da Alemanha, onde Piscator e, em outra medida, Reinhardt, cada um à sua maneira, renovam a cenografia pelas técnicas mais avançadas da época. A relação ilusionista, convencional ou naturalista no teatro sofre uma reviravolta. O tratamento da escuridão/breu [noir] e a ocultação da cena fazem parte disso e continuarão a sugerir aos diretores e cenógrafos propostas cenográficas e dramatúrgicas que quebram o ritual ou o reforçam com a consciência de dele fazer parte. (Perruchon, 2016, p. 226-227). ${ }^{11}$

Veronique Perruchon atenta para o fato de que uma das grandes renovações técnicas e estéticas desse período, mesmo promovida pelas tecnologias da iluminação, está ligada ao potencial de jogo com o escuro na cena, a capacidade de obscurecer partes do palco/cena. Tal jogo está diretamente relacionado à capacidade narrativa de escolha do que mostrar e do que não mostrar, quando e como fazê-lo. Temos de ter clareza de que estamos falando do surgimento de novas convenções gerando linguagens para comunicação com o público:

Uma convenção, no sentido mais simples, é só um método, uma peça técnica da maquinaria, que facilita o espetáculo. Mas os métodos mudam e as técnicas mudam, e enquanto, digamos, um coro de dançarinos, ou o manto de invisibilidade, ou um solilóquio cantado são conhecidos métodos dramáticos,

\footnotetext{
11 Il ne fait pas de doute que la France dans les années vingt, marche sur les traces de l'Allemagne où Piscator et dans une autre mesure, Reinhardt, chacun à sa manière rénove la scénographie par les techniques les plus poussées de l'époque. Le rapport illusionniste, conventionnel ou naturaliste au théâtre est bouleversé. Le traitement du noir et l'occultation de la scène en font partie et continueront à suggérer aux metteurs en scène et décorateurs des propositions scénographiques et dramaturgiques qui cassent le rituel ou le renforcent avec conscience d'en jouer. (Tradução nossa)
} 
eles não poderão ser satisfatoriamente utilizados a não ser que, à época do espetáculo, sejam mais que métodos, a não ser que eles sejam convenções. Dramaturgos, atores e público devem ser capazes de concordar que o método particular a ser empregado é aceitável; e, dependendo do caso, uma parte importante desse acordo deve usualmente preceder o espetáculo, de modo que o que está por ser feito seja aceito sem ficções danosas (Williams apud Ramos, 2010, p. 9).

Hoje, talvez seja simples pensar uma cena que se passa num mesmo palco em dois ou três espaços ficcionais ou até em diversos tempos ficcionais. Em meados do século XX, porém, tal disposição espacial geraria confusões de compreensão da escrita cênica, posto que a iluminação, ao pontuar cada espaço - em momentos e com características visuais específicas e diversas -, conduzia o público, junto ao texto, para a compreensão do que se passava narrativamente. Assim, iluminar ou não iluminar, ou seja, mostrar de forma controlada, a partir de um roteiro prévio que constrói para o público uma narração, é um ato possível graças ao potencial de esconder como base do mostrar, da possibilidade do escuro como base para a luz.

A grande novidade da iluminação elétrica, portanto, não é apenas a qualidade da luz, é a possibilidade da não luz, que ofuscada pela lâmpada acesa demorará décadas para ser percebida. Além de dar visibilidade, a iluminação cênica ganhou o poder de esconder. Num piscar de olhos faz aparecer e desaparecer a cena, ou parte dela. Através do movimento entre a luz e as trevas, e suas miríades de combinações, o teatro acessa além do visível, o invisível; e através dele a sugestão, a comunicação possível daquilo que é indizível (Simões, 2008, p. 220).

Piscator utilizou-se muito da luz e de outros recursos tecnológicos para realizar tais novas convenções: a já dita projeção, tapetes rolantes, palcos giratórios, pontes motorizadas etc. $\mathrm{E}$, como já vimos, esses recursos propiciavam o que percebemos e chamamos no teatro de Piscator de cena simultânea, que, reiteramos, tem a ver com a relação entre a cena e a história. Exatamente o que a iluminação proporcionou de forma mais radical, nos parece, pela leitura de seu texto "Ideas sobre una renovación del arte escénico mediante la luz", de 1953, escrito para o programa do espetáculo A engrenagem, de Jean-Paul Sartre, no Städttische Bühne, de Frankfurt (Piscator, 2013, p. 167). De alguma forma, a luz potencializa o jogo entre planos de sentido e cena que as demais tecnologias, incluídas as cinematográficas, proporcionavam no teatro de Piscator. Vamos ver como?

Sabemos que o teatro épico, investigado e desenvolvido por Piscator e pelo diretor e dramaturgo Bertolt Brecht (1898-1956) entre finais do século XIX e início do XX, como nos demonstra Peter Szondi (2001), é profundamente devedor do movimento naturalista de André Antoine, Otto Brahm (1856-1912) e Constantin Stanislavski (1863-1938). A característica fundamental herdada pelo movimento de teatro político dos anos 1920 é a referência histórica. A história é tema e problema da cena épica, como já indica a expressão teatro épico e como já vimos na teoria e prática cênica de Piscator. Seguindo a análise realizada no artigo "Apontamentos sobre a história da iluminação moderna: a parceria entre tecnologia e cena" (Nosella, 2019), sabemos que a iluminação elétrica é fator determinante para as renovações cêni- 
cas que desembocarão no que conhecemos hoje como teatro moderno em seus dois movimentos estéticos fundantes: naturalismo e simbolismo. Se no naturalismo a iluminação possibilitou o que ficou conhecido como teatralidade do real, que poderíamos resumir na capacidade de instaurar uma realidade espacial e cenográfica no palco todo, criando uma efetiva tridimensionalidade no cenário, em oposição à ilusão tridimensional da perspectiva, no simbolismo a luz elétrica possibilitou a aspiração a uma linguagem da iluminação e seu incremento pelo não dizível, pelo não específico. Se o naturalismo, pela iluminação, define a especificidade histórica, social e econômica do espaço, o simbolismo abstrai essa especificidade para buscar dizer algo para além desse espaço; porém, ambos, a fim de conseguir seus intentos, precisam do referido controle a distância das fontes luminosas.

Através de procedimentos similares aos da poesia, o teatro simbolista usa das elipses e metáforas da imagem, para atingir seu ideal de "síntese e sugestão", excitando a imaginação da plateia a participar criativamente da cena. O teatro atravessa o visível rumo ao invisível e recria a realidade em cena segundo a subjetividade, inspirado pela abstração transcendente da música, com a parceria concreta dos poetas simbolistas e dos pintores modernos. A sinestesia tece uma rede de relações sensoriais entre a música, o texto, a pintura e a iluminação nos espetáculos teatrais. (Simões, 2008, p. 222).

Ao épico, nesse sentido almejado por Piscator, nos parece confluir ambos os intentos. Já verificamos que Piscator almeja o histórico em cena, porém não mais (ou apenas) o histórico naturalista; não mais a instauração de um contexto histórico específico e único. A história, enquanto passado, no entender de Piscator, perpassa o tempo da ficção como um fantasma a nos assombrar continuamente. Olhar para a história ou materializá-la em cena é uma forma de sobrepor o passado ao presente, comentando-o, "iluminando-o", com preocupação pelo futuro, almejando o futuro, a revolução. Nesse sentido, a busca de Piscator visa sobrepor o histórico (épico) ao dramático e, para isso, sobrepõe a tecnologia (futuro), como documento da história (passado), na cena/drama (presente). Para fazê-lo, Piscator utiliza de forma exaustivamente experimental todo aparato técnico que tem à disposição, incluída a iluminação elétrica, com o intuito de produzir camadas de significado a partir da fragmentação da cena, e não apenas no contexto do palco, mas para além dele.

Esta máquina teatral refutava a câmara ótica que por meio do pano e cova da orquestra mantinha o espectador separado do palco. Ao invés de único centro de atenção, multiplicavam-se os palcos em cena (um central e dois laterais) e engrenagens que envolviam e cercavam o público distribuído em torno desses palcos. Assim, de todas as direções as performances se abatiam sobre o público. A audiência pertence espacialmente ao palco, e vê-se confrontada e tomada pelas performances, meios mecânicos e projeções luminosas. (Mota, 2012, p. 55).

A luz para Piscator, ao contrário do que ocorreu com o naturalismo, tinha a capacidade de isolar e "deformar" o sentido espacial - "Cuando las personas pueden caminhar sobre luz, se desvinculan del espacio" (Piscator, 2013, p. 167). Ele parece perceber aquilo que a luz simbolista revela: mais do que iluminar um espaço ou um 
objeto, ela cria um espaço próprio. Esse espaço está fora do contexto espacial da cena, fora da história, mas sem a negar. No jogo de claro e escuro, de revelar e esconder o que se quer, criando espaços e relações entre eles, não se negam o tempo e a história, que são antes manipulados, presentificando o passado e imaginando um futuro pelos olhos de ontem. Segundo Piscator, isso se dá exatamente pela possibilidade que temos desde então de modificar a forma de iluminar, subvertendo o olhar naturalista. "Hasta ahora se iluminanaba la cabeza o el lateral, se iluminaba desde arriba, desde delante, desde atrás. Ahora será desde abajo" (Piscator, 2013, p. 167).

Esse potencial da luz revela ao encenador a força de convergir todo o conjunto de recursos técnicos de narratividade do palco. "Toda la técnica del teatro tendrá que subordinarse a la luz" (Piscator, 2013, p. 167), e dela surgirá uma nova cena, uma nova dramaturgia, pois essa possiblidade de criar espaços, onde e como se deseja, estabelece novas leis para toda a cena. Novas leis para o gesto, para o movimento e até mesmo para a palavra.

Piscator propõe nesse texto que todo o aparato técnico já experimentado por ele, com o intuito de fragmentar o espaço e o tempo no palco a fim de estabelecer o diálogo entre passado, presente e futuro, entre ficção e realidade, seja substituído pela tecnologia da iluminação. Ao fazê-lo, está propondo a constituição do que ele chama de um cenário de luz.

\footnotetext{
El escenario de luz traerá la liberación de la técnica, pues a través de sí mismo lleva la técnica a su última, máxima y más refinada expresión. Cine, proyección, cinta transportadora, escenarios de pisos y globo, discos giratorios y puentes motorizados (recursos que yo mismo he utilizado) solo ahora empiezan a estar prontos para su uso como aportadores y modificadores invisibles o visibles de las imágenes de la acción dramática. (Piscator, 2013, p. 168).
}

O cenário de luz tem o potencial de revelar o que não está à vista, pois a luz permite o jogo de significação do indizível e do invisível, como aprendemos com os simbolistas. Nesse sentido, ela pode revelar a história por trás da cena, o passado por trás do presente, realizando o potencial simbolista, sem negar as aspirações históricas naturalistas. Ao criar o cenário de luz, a iluminação elétrica possibilita a Piscator a encenação de uma história em camadas, nos permitindo ver através delas. "El escenario de luz puede producir radiografías del arte" (Piscator, 2013, p. 168).

\section{Confere}

Confere, reiteramos, é um experimento cênico desenvolvido pelo Coletivo Fuzuê no âmbito do Grupo de Pesquisa em História, Política e Cena da UFSJ e seus dois núcleos de estudos, já citados e descritos na introdução deste artigo. Retomamos tais informações apenas para destacar que o Coletivo Fuzuê não se configura como um grupo de teatro e nem Confere como um espetáculo em sentido estrito, uma vez que, mesmo sendo de extrema importância o acabamento formal e a qualidade estética do trabalho, o fim primeiro é a investigação e a formação, de base laboratorial, teórico-prática. No caso específico, esse fim envolveu a prática artística e o pensamento de Erwin Piscator e o teatro épico, no que concerne principalmente à 
direção teatral, às estruturas narrativas e políticas da cena, à iluminação cênica e aos sentidos visuais e técnicos de seu fazer.

O estudo teórico e histórico do pensar e do fazer da cena e seus desdobramentos laboratoriais - pela perspectiva da direção da cena e da iluminação - tanto produzem conhecimento e reflexão levantando informações sobre o trabalho de Piscator e suas práticas cênicas quanto acrescentam ao processo de formação de discentes nos níveis de graduação e pós-graduação. E esse é o fim primeiro do trabalho, que tem como um de seus resultados o experimento cênico Confere.

Além desse fim primeiro, o experimento cênico tem ainda outro fim, anterior ao estritamente artístico, que é servir de meio de divulgação para o conhecimento e a reflexão sobre Piscator e o teatro épico e para o processo de formação ali desenvolvido (assim como o é o presente artigo). Nem precisaríamos mencionar que tais fins primeiros são fundamentais para se entender o processo, a proposta e os resultados do trabalho. Porém, é importante lembrar que eles não diminuem a preocupação com a qualidade estética e artística entendida como resultado do produto Confere, pois, sem ela, mesmos os fins primeiros perderiam sua validade, uma vez que estamos no campo da pesquisa em artes cênicas. Talvez, entretanto, essa preocupação desloque certo entendimento da própria noção de qualidade estética e artística, não mais como uma proposição formal que busca se "inovar", ou "inovar" o próprio campo do fazer cênico, mas antes se constituindo muito mais pela compreensão e pela reflexão sobre o acúmulo e decantamento de conhecimento que conformam o fazer artístico e seus resultados, ou seja, a historicidade das práticas e estéticas, seu estudo e sua reelaboração em cena pelos alunos em formação.

Nesse sentido, a estrutura básica da encenação de Confere foi pensada no jogo e na articulação entre a dimensão histórica específica e a representação dessa dimensão para além de sua especificidade, como vimos na presença da história na cena de Piscator, devedora do naturalismo; e em sua proposição de uma nova cena que transcenda esse histórico, nos revelando suas diversas camadas espaciais e temporais, por meio do uso da técnica e da estética da iluminação elétrica proposto pelo simbolismo.

O cenário e sua constante manipulação pelos atores na constituição de diversas cenas - sempre num mesmo espaço e com os mesmos objetos a constituir diversos espaços - propõem exatamente que cada espaço seja transpassado pelos demais, anteriores e ainda por vir. Nesse contexto, a ideia de um "cenário ruína" tanto resolve tecnicamente a proposta - uma vez que não há um espaço real representado, mas pedaços de objetos e coisas, bancos e mesas soltos e desmontados que, agrupados e posicionados de formas diversas pelos atores, sugerem representações - quanto realiza a proposta espacial abstrata por trás da ideia central da peça: de que na verdade vivemos sobre acúmulos de escombros e ruínas legados por nosso passado. No jogo temporal, não é à toa que tal ideia se revela de forma alegórica apenas na cena final da peça, na qual é posto o anjo da história de Walter Benjamin (1987, p. 226):

Há um quadro de Klee que se chama Angelus Novus. Representa um anjo que parece querer afastar-se de algo que ele encara fixamente. Seus olhos estão escancarados, sua boca dilatada, suas asas abertas. $O$ anjo da história deve ter 
esse aspecto. Seu rosto está dirigido para o passado. Onde nós vemos uma cadeia de acontecimentos, ele vê uma catástrofe única, que acumula incansavelmente ruína sobre ruína e as dispersa a nossos pés. Ele gostaria de deter-se para acordar os mortos e juntar os fragmentos. Mas uma tempestade sopra do paraíso e prende-se em suas asas com tanta força que ele não pode mais fechá-las. Essa tempestade o impele irresistivelmente para o futuro, ao qual ele vira as costas, enquanto o amontoado de ruínas cresce até o céu. Essa tempestade é o que chamamos progresso.

Essa cena final revela, como a radiografia almejada por Piscator, o que está por trás da cena, ao elaborar visualmente a alegoria do anjo de Benjamin que, impelido para o futuro pelo progresso, percebe os escombros que se acumulam, mas não pode agir, pois não consegue parar. Interromper o fluxo para percebermos o que de fato nos cerca, a tragédia que sobre nossos pés está assentada, é o desejo expresso por Georg Büchner desde a análise do processo histórico da Revolução Francesa em sua peça A morte de Danton:

Lucile - [...] Tudo se move, os relógios andam, os sinos repicam, as pessoas correm, a água escorre, e assim, assim tudo segue até aí, até lá - não!, não pode acontecer, não - eu quero me sentar no chão e gritar para que tudo pare de susto. Tudo estaque, não mais se mova. (Ela senta-se no chão, cobre os olhos com as mãos e solta um grito. [...] (Buchner, 2004, p. 163).

Na composição dessa cena, uma luz de "fantasia" rosa e vermelha, para qual foram utilizados os filtros rose e medium red ${ }^{12}$, varre o palco lateralmente, lembrando chamas e a esperança na revolução, como alento e autocrítica, proporcionando a valorização dos volumes com o alto-contraste próprio da luz lateral. Tal valorização deforma ainda mais os objetos em suas singularidades, potencializando a sensação de um conjunto de escombros e ruínas em torno da cena. Ao mesmo tempo em que uma luz lavanda ${ }^{13}$, provocando um resfriamento do ambiente, atinge as asas do anjo que, abertas, procuram, sem sucesso, se opor àquele cenário. Tal oposição se revela no contraste das cores - rosa e vermelho versus lavanda - e é intensificada pelo contrabranco ${ }^{14}$ intenso, vindo de baixo para cima, formando uma espécie de aura em torno da figura do anjo, como se fosse ainda outro contraste: uma luz vinda do futuro do anjo, às suas costas, que não é possível enxergar, tanto porque o próprio anjo está na nossa frente - impedindo vislumbrar o que está atrás dele (e em nosso futuro) quanto porque a luz que dali emana nos cega (Figura 1).

\footnotetext{
12 Rosco Supergel 45 e 27, respectivamente. Informação disponível em: <http://roscobrasil.com.br/downloads/guiasupergel.pdf>.

13 Filtro lavender (Rosco Supergel 57).

14 Tecnicamente, com relação à categoria iluminação, não se trata de luz branca, que seria estritamente a junção de todas as frequências do espectro luminoso; e no que tange à luz produzida por fontes artificiais, poderíamos chamar de "luz do dia" cuja temperatura de cor varia entre 5000K e 5500K. Nesse caso, com uso de lâmpadas incandescentes halógenas de 1000W, que possuem temperatura de cor entorno de 3200K, a luz seria o que chamamos de "amarelada". Porém, por convenção visual, e no jogo de contraste com o uso dos filtros de cor, o público codifica essa luz amarelada, sem uso de filtro de cor, como luz branca. Assim deve ser entendida a ideia de luz branca no conjunto deste trabalho.
} 


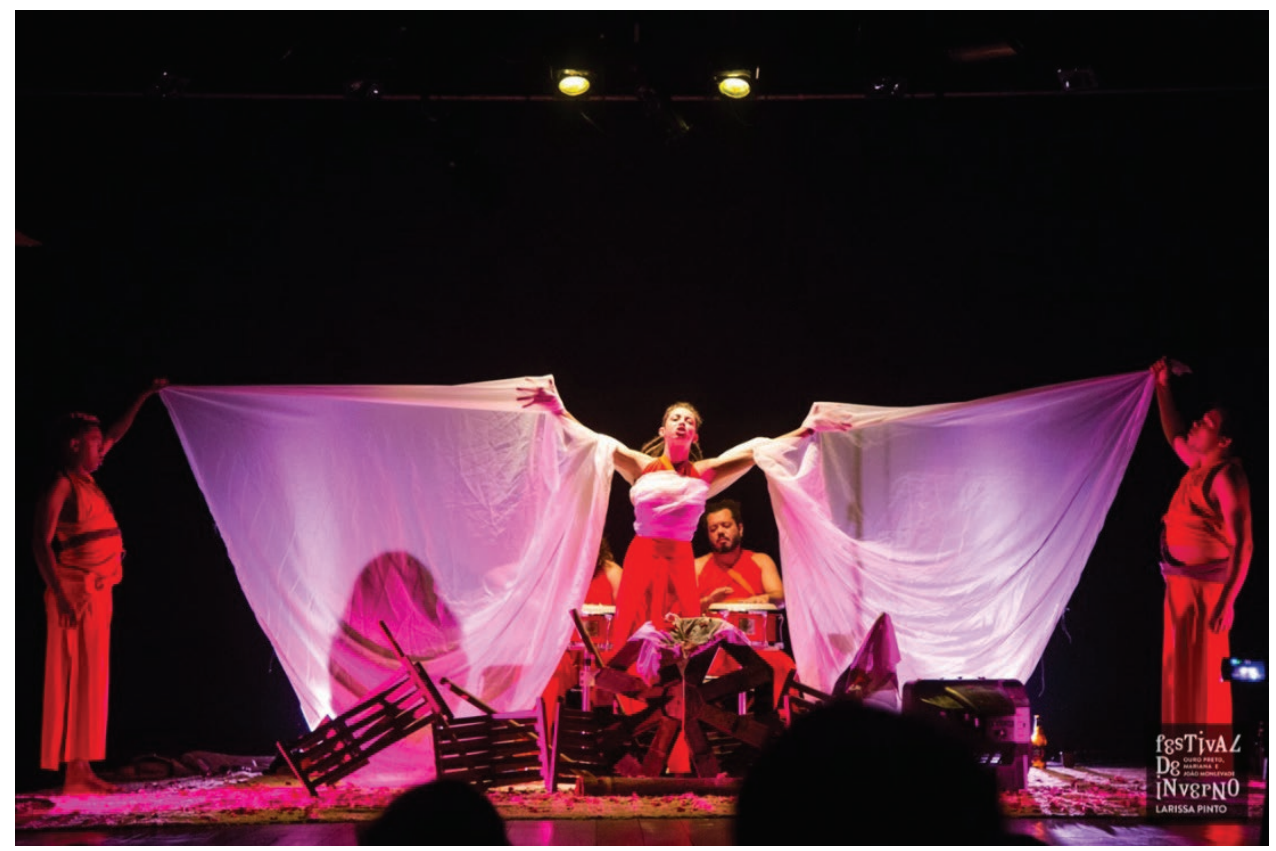

Figura 1: Cena do anjo, apresentação no Festival de Inverno de Ouro Preto e Mariana

Foto: Larissa Pinto

Em nossa compreensão da peça, tal cena se destaca e abre este subcapítulo analítico, por permitir a convergência dos processos de trabalho formativo quanto à cena dialética épica numa alegoria que sintetiza tanto o processo quanto o produto, estabelecendo o diálogo/debate com o público. O sentimento do momento histórico presente e os estudos a seu respeito (empreendidos pelo grupo) estão plasmados no sentimento de um mundo que desmorona cotidianamente, na percepção das restrições sociais e econômicas. Esse desmoronamento, percebido e sentido pelos alunos no presente, é o ponto de partida para a compreensão desse mesmo sentimento em outras situações históricas e das formas estéticas cênicas que procuraram dar respostas a esse sentimento em outros momentos. Desse conhecimento, que transita entre presente e passado, é que se desenvolve o processo de reelaboração na cena atual das formas cênicas já experimentadas por Piscator, entendendo que aquilo que resiste como linguagem não é nem cópia, nem repetição, mas sim um sintoma daquilo que resiste na história e precisa ser mudado. Esse processo costura de forma intrínseca o produto e seu meio de produção num conjunto que experimentamos como processo de formação, tanto dos estudantes/artistas envolvidos quanto de cada espectador a que se propõe a obra enquanto início de debate, e não fim.

Outra cena que gostaríamos de analisar é a da novela, que os atores "montam" com os elementos/escombros do cenário, dispondo-os em diversos espaços simultâneos. Do lado direito à frente, uma mesa e um aparelho de TV, que emite para a cena (oposto ao público) uma luz azulada, iluminando duas amigas que assistem à novela. Do lado esquerdo à frente, um casal encena a novela que está sendo vista pelas amigas na TV, iluminados pelo branco frontal e por um tom verde-azulado (lime green 088, Lee Filters). Ao fundo, o estúdio em que as trucagens e sonoplastias da novela, não visíveis aos espectadores da TV, são realizadas à nossa vista, iluminado de branco e recortado por elipsoidal. Nessa cena, que se repete em dois momentos do experimento, aludindo à repetição nas estruturas narrativas das novelas, a luz realiza 
a função de definição narrativa da espacialidade, informando ao público que cada um daqueles espaços, estando fisicamente juntos no palco, são ficcionalmente distintos. Essa cena, exatamente, resgata e investiga o dispositivo de iluminar e ocultar partes distintas do palco a fim de manipular narrativamente o tempo e o espaço em cena, criando o jogo, hoje tão comum, das cenas simultâneas (Figura 2).

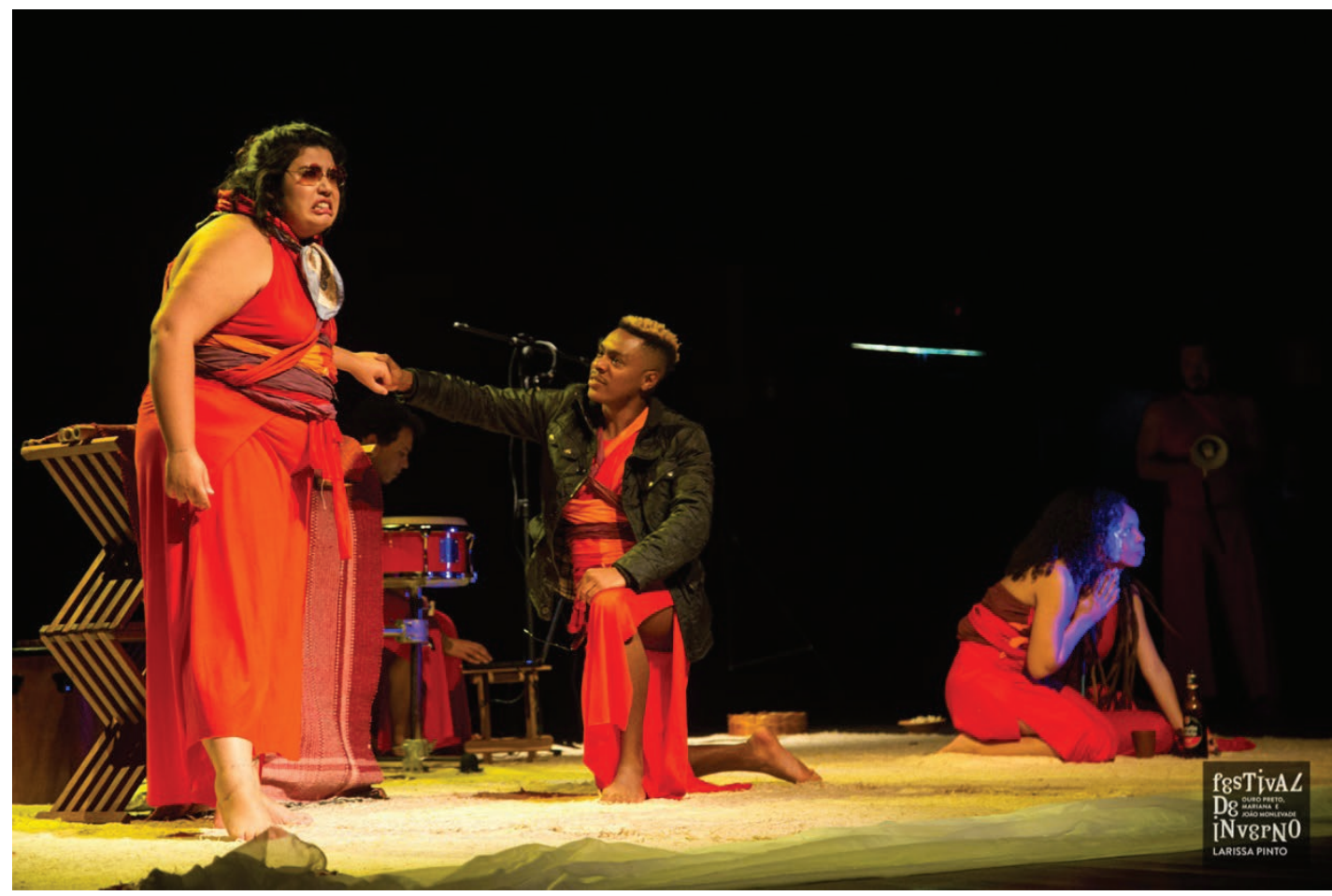

Figura 2: Cena da novela, apresentação no Festival de Inverno de Ouro Preto e Mariana Foto: Larissa Pinto

A presença da TV tem relação direta com o debate histórico proposto pela ideia geral da peça, dos escombros e ruínas em que estamos assentados sem perceber, uma vez que tais tecnologias da comunicação são, no entendimento da peça, responsáveis pela constituição desse estado das coisas - tanto da própria ruína quanto de sua não percepção. Essa discussão sobre o uso da tecnologia e sua relação com os meios de difusão cultural em nossa realidade, trazida à cena, dialoga diretamente com o atual momento político de nosso país e, ao mesmo tempo, revela o processo histórico que constituiu este presente

Todos os que até hoje venceram participam do cortejo triunfal em que os dominadores de hoje espezinham os corpos dos que estão prostrados no chão. Os despojos são carregados no cortejo, como de praxe. Esses despojos são os que chamamos de bens culturais. Todos os bens materiais que o materialista histórico vê têm uma origem que ele não pode contemplar sem horror. Devem sua existência não somente ao esforço dos grandes gênios que os criaram, como à corveia anônima de seus contemporâneos. Nunca houve um monumento de cultura que também não fosse um monumento da barbárie. E, assim como a cultura não é isenta de barbárie, não o é, tampouco, o processo de transmissão da cultura. (Benjamin, 1987, p. 225).

Destacamos aqui a última parte da cena Whatsapp, que traz uma representação 
de pessoas em diálogo pelo celular, defendendo o período da ditadura militar no Brasil. O diálogo termina com alguém afirmando que só pessoas de conduta duvidosa sofreram durante aquele período. Um corte, e a cena passa a narrar de forma intrincada duas histórias de morte de estudantes, a de Edson Luiz de Lima Souto e Marcos Vinícius da Silva. Edson Luiz era secundarista e durante a repressão a uma passeata que aconteceu no dia 28 de março de 1968 - período em que o Brasil passava por uma ditadura militar - foi morto com um tiro à queima-roupa, quando a polícia militar invadiu o Restaurante do Calabouço, no Rio de Janeiro. Marcos Vinícius faz parte de uma história mais recente, que aconteceu na carioca Favela da Maré, em 20 de julho de 2018 - período em que a cidade do Rio de Janeiro passava por intervenção militar, assinada pelo então presidente Michel Temer, justificada pelo objetivo de "intensificar a segurança pública" -, durante uma operação da polícia militar na comunidade; trajando seu uniforme de escola pública, o estudante foi morto com um tiro nas costas. A montagem do entrecruzamento das histórias resulta em um vai e vem histórico e costura a temática da violência e truculência militar na nossa história, buscando, assim, na ideia de montagem, apresentar o contexto histórico (político, econômico e social) em relação às histórias pessoais.

No caso desta última cena e da questão da tecnologia, a iluminação, que se propõe branca em todas as cenas, pinta o espaço em que a tecnologia age, ou seja, que as mensagens de WhatsApp procuram difundir informações não verificadas e atestadas como verdadeiras, com um verde-azulado, de tonalidade metálica, um pouco incômoda e bem diversa da representação mais realista do branco (lime green 088, Lee Filters). Isso visa criar um código que permite no jogo entre luz e cena pontuar esses momentos na leitura proposta pela peça, destacando as situações de interferência dos meios tecnológicos de comunicação, ou seja, a luz torna-se a voz da posição política da cena (Figura 3). 


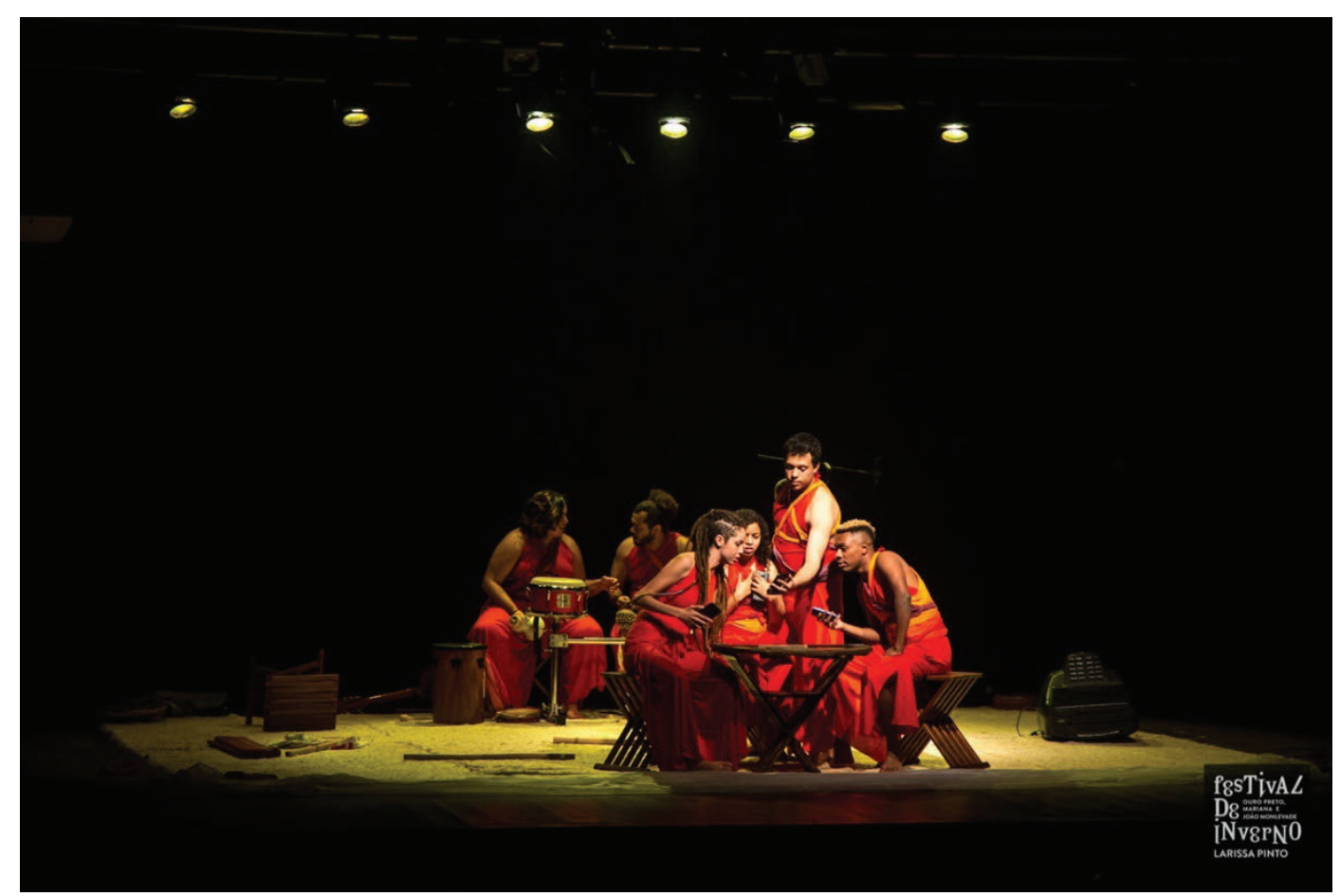

Figura 3: Cena do whatsapp, apresentação no Festival de Inverno de Ouro Preto e Mariana Foto: Larissa Pinto

Por outro lado, o que poderíamos chamar de contracena, em que se cruzam as histórias de Edson Luiz de Lima Souto e Marcos Vinícius da Silva, é iluminado lateralmente e a partir do chão pelo rosa já citado e pela contraluz branca. Na frente da cena, entre ela e o público, estende-se um tule branco, buscando tanto a sensação de uma tela de cinema quanto de um certo "embaçado", uma vez que essa cena é um resgate de uma narrativa do passado que tem por objetivo contradizer as mensagens trocadas na cena do whatsapp. O contraste é dado pela configuração da cena - possibilitada pelo jogo de luz lateral atrás do tule, truque conhecido desde sempre e muito usado pelos encenadores do final do século XIX e início do XX - e pelo contraste da cor entre as duas cenas, verde-azulado em uma, mais frio e um tanto enjoativo; rosa e branco na outra, mais quente e criando um ambiente acolhedor na representação das crianças que serão brutalmente mortas na sequência. Tal cena, termina com o som do tiro e um blackout rápido, deixando ao breu a imaginação da plateia.

\section{Considerações finais}

Trazendo à tona o diálogo com a história e os fatores sociais, políticos e econômicos, os laboratórios cênicos do GPHPC, em seus dois núcleos e em suas especificidades, buscam tanto a pesquisa, teórica e histórica, quanto a aplicação dos procedimentos cênicos e dramatúrgicos em cena. Isso se tem mostrado profícuo, trazendo até o momento como resultado, além de experimentos cênicos (produções 
artísticas), o desenvolvimento de práticas formativas em diversos níveis. No campo da iluminação cênica, buscamos apresentar aqui um quadro geral do conjunto de conhecimentos e resultados que a prática cotidiana de um grupo de trabalho ligado a uma universidade pública brasileira pode gerar. A partir da análise das ideias e práticas de um importante encenador do início do século $X X$, que incorporou de forma criativa e contundente as novas tecnologias da segunda revolução industrial (1850-1870), até a aplicação desse conhecimento no desenvolvimento de produtos e reflexões artísticas, o Grupo propõe um amplo quadro de ações. Ações que tanto contribuem para o desenvolvimento dos conhecimentos históricos como deles se alimenta. $\mathrm{E}$ acreditamos que essa é uma forma eficaz e contundente de pesquisar e aprender sobre a luz, a cena e as intrincadas relações entre elas.

Nesse processo de criação da luz, como pudemos verificar, os alunos, especificamente os do Netoc, constataram como o uso da luz pode potencializar a narrativa da cena não apenas em sua concretude presente, mas na definição de linguagens que, como vimos, são convenções criadas historicamente e difundidas culturalmente. O estudo e a manipulação dessas convenções, acreditamos, potencializa o conhecimento e o exercício criativo dos futuros artistas da cena, tornando-os conhecedores da história e capazes de analisá-la e criticá-la artisticamente. Assim esperamos.

\section{Referências}

BENJAMIN, Walter. O autor como produtor. In BENJAMIN, W. Ensaios sobre Brecht. Trad. Claudia Abeling. São Paulo: Boitempo, 2017, p. 71-164.

BENJAMIN, Walter. Obras escolhidas. Vol. 1. Magia e técnica, arte e política. Ensaios sobre literatura e história da cultura. Tradução de Sérgio Paulo Rouanet. São Paulo: Brasiliense, 1987.

BUCHNER, Georg. A morte de Danton. In GUINSBURG, Jacó; KOUDELA, Ingrid Dormien (organização e tradução). Büchner: na pena e na cena. São Paulo: Perspectiva, 2004, p. 71-164.

EISENSTEIN, Sergei. A forma do filme. Zahar, 2017 (e-book).

GRAZIOLI, Cristina. Luce e ombra: storia, teorie e pratiche dell'illuminazione teatrale. Roma-Bari: Laterza, 2015 (e-book).

MOTA, Marcus. Fontes para os estudos teatrais I: contribuições de A. Appia e E. Piscator. Urdimento, v.1, n.18, Florianópolis. Disponível em <http://www.revistas.udesc.br/ index.php/urdimento/article/view/1414573101182012043/2341>. Acesso em: 27 out. 2019. 2012.

NOSELLA, Berilo L. D. Apontamentos sobre a história da iluminação moderna. Revista ArteDaCena (Arton Stage), v.4, n.2,UFG.DOI:<https://doi.org/10.5216/ac.v4i2.54795>. 
Disponível em <https://www.revistas.ufg.br/artce/article/view/54795/32608>. Acesso em: 27 out. 2019.

PERRUCHON, Véronique. Noir, lumière et théâtralité. Villeneuve-d'Ascq: Presses Universitaires du Septentrion, 2016.

PISCATOR, Erwin. Ideas sobre una renovación del arte escénico mediante la luz. In: HERNANDO, César de Vicente (org.). Erwin Piscator: teatro, política, sociedad. Traducción de Cristina Díez Pampliega. Madrid: Publicaciones de la Asociación de Directores de Escena de España (ADE), 2013, p. 167-169.

PISCATOR, Erwin. Teatro político. Rio de Janeiro: Civilização Brasileira, 1968.

RAMOS, Luiz Fernando. Prefácio. In: WILLIAMS, Raymond. Drama em cena. Trad. Rogério Bettoni. São Paulo: Cosac Naify, 2010, p. 7-16.

ROSENFELD, Anatol. História da literatura e do teatro alemães. São Paulo: Perspectiva, 1993.

SCHINO, Mirella. Alquimistas do palco: os laboratórios teatrais na Europa. São Paulo: Perspectiva, 2012.

SIMÕES, Cibele Forjaz. À luz da linguagem: a linguagem da iluminação cênica de instrumento da visibilidade à dramaturgia do visível (primeiro recorte: do fogo à revolução teatral). Dissertação (Mestrado em Artes Cênicas) - Escola de Comunicações e Artes, Universidade de São Paulo, São Paulo, 2008.

SZONDI, Peter. A revista política. In: Teoria do drama moderno (1880-1950). São Paulo: Cosac Naify, 2001, p. 127-132.

Recebido em: 30/10/2019

Aprovado em: 07/02/2020 